
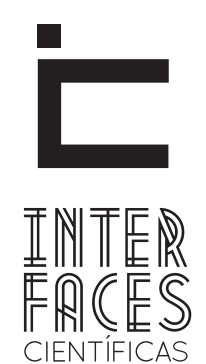

EDUCAÇÃO

ISSN IMPRESSO 2316-333X

E-ISSN 2316-3828

DOI 10.17564/2316-3828.2016v4n2p 71-82

\title{
GÊNEROS TEXTUAIS E VARIAÇ̃̃o LINGUISTICA NA PROVA DE LINGUAGENS, CÓDIGOS E SUAS TECNOLOGIAS DO ENEM
}

\section{RESUMO}

Partindo do princípio de que o Enem tem como função primeira de avaliar e, consequentemente, auxiliar na elaboração de políticas públicas destinadas à última etapa da educação básica, a proposta deste trabalho é investigar como se dá uso dos gêneros textuais como suportes às questões que tratam de variação linguística na prova de Linguagens, Códigos e suas Tecnologias, no período de 1998 a 2012.
Raquel Meister Ko. Freitag ${ }^{2}$

\section{PALAVRAS-CHAVE}

Variação Linguística. Gêneros Textuais. Enem. 


\section{ABSTRACT}

Considering that Enem's principal function is proceeding at the evaluation of all educational cycle and hence subsiding the proposition of public policies to final cycle of basic, this papers presents an investigation about the use of textual genres as support to the questions that approach the linguistic variation in Linguagem, Código e suas Tecnologias assessment of Enem, in the period from 1998 at 2012.

\section{RESUMEN}

Suponiendo que el Enem tiene función principal la evaluación y, por lo tanto, ayudar en la elaboración de políticas públicas para la última etapa de la educación básica, el propósito de este trabajo es investigar cómo ocurre el uso de géneros textuales como soporte a cuestiones acerca de la variación lingüística en el examen de idiomas, Códigos y sus Tecnologías, desde 1998 hasta el 2012.

\section{KEYWORDS}

Linguistic variation. Textual genres. Enem

\section{PALABRAS CLAVE}

Variación lingüística. Géneros Textuales. ENEM 


\section{INTRODUÇ̄̃̃O}

O Exame Nacional do Ensino Médio (Enem) foi criado por meio da Portaria do Ministério da Educação $n^{\circ}$ 438, de 28 de maio de 1998, com o objetivo de avaliar o desempenho do estudante ao fim da educação básica, inicialmente visando contribuir com a melhoria da qualidade da educação pública. A partir de 2009, com a portaria $n^{0} 109$, de 27 de maio de 2009, este exame passou a ser utilizado, também, como mecanismo de seleção para o ingresso no ensino superior, além de funcionar como instrumento para o acesso a programas do governo federal, como o Programa Universidade para Todos (PROUNI), que foi criado pela Lei da Presidência da República, nº 11.096/2005, cuja finalidade é a concessão de bolsas de estudos integrais e parciais a estudantes de cursos de graduação e de cursos sequenciais de formação específica, em instituições privadas de educação superior.

Em decorrência da instituição do Programa de Apoio a Planos de Reestruturação e Expansão das Universidades Federais (REUNI), com o decreto $n^{0}$ 6.096, de 24 de abril de 2007, as universidades federais começaram a aderir ao Novo Enem como método de seleção de candidatos para as vagas ofertadas, a fim de atender premissa de ampliação do acesso à educação superior, prevista como objetivo maior do programa, a exemplo da Universidade Federal de Sergipe, que, com a Resolução $n^{0}$ 21/2009/CONEPE, regulamentou que o processo seletivo passaria a utilizar as notas do Enem para classificar os candidatos ao ingresso nos cursos de graduação.

Segundo edital $n^{0} 12$, de 8 de maio de 2014, as informações obtidas a partir dos resultados do Enem podem ser utilizadas para: i) Compor a avaliação de medição da qualidade do Ensino Médio no País; ii) Subsidiar a implementação de políticas públicas; iii) Criar referência nacional para o aperfeiçoamento dos currículos do Ensino Médio; iv) Desenvolver estudos e indicadores sobre a educação brasileira; v) Estabelecer critérios de acesso do participante a programas governamentais; vi) Constituir parâmetros para a autoavaliação do participante, com vista à continuidade de sua formação e à sua inserção no mercado de trabalho; vii) Certificar nível de conclusão do Ensino Médio; vi) Servir como mecanismo de acesso à Educação Superior ou em processos de seleção nos diferentes setores do mundo do trabalho.

Com o acúmulo de funções do Enem ao longo dos anos, além das previstas no edital, a partir do ano de 2014, uma instituição europeia, a Universidade de Coimbra, passou a fazer o uso das notas do exame para selecionar candidatos brasileiros para os cursos de graduação, uma vez que existe um interesse expressivo desses pela universidade portuguesa, que atualmente já possui 2.059 alunos matriculados.

Além de se tornar porta de entrada para o ensino superior, a nota do exame se tornou ferramenta importante nessa etapa do ensino, haja vista que as médias obtidas por meio da prova também passaram a ser critério para as seleções do Programa Ciências sem Fronteiras, que se destina à concessão de bolsas de intercâmbio para que alunos de graduação e pós-graduação façam estágio no exterior. 0 candidato que deseja participar das seleções deve ter como nota mínima 600 pontos no exame.

Ainda como efetivação de políticas públicas, o Enem compõe o documento do Plano Nacional de Educação (PNE), que por intermédio da Lei presidencial $n^{\circ} 13.005$, de 25 de junho de 2014, apresenta a nota do exame como uma das estratégias previstas para a garantia da meta de número 13 do plano:

Elevar a qualidade da educação superior, a medida que propõe substituir o Exame Nacional de Desempenho de Estudantes - ENADE aplicado ao final do primeiro ano do curso de graduação pelo Exame Nacional do Ensino Médio - Enem, a fim de apurar o valor agregado dos cursos de graduação". 
E principalmente, no que se refere à educação básica, a estratégia de

Incorporar o Exame Nacional do Ensino Médio, assegurada a sua universalização, ao sistema de avaliação da educação básica, bem como apoiar o uso dos resultados das avaliações nacionais pelas escolas e redes de ensino para a melhoria de seus processos e práticas pedagógicas.

Está vinculada à meta 7: "Fomentar a qualidade da educação básica em todas as etapas e modalidades”.

Dada sua amplitude e relevância no cenário educacional, é de se esperar que o exame tenha se tornado alvo de estudos e críticas, o que fez com que passasse por mudanças e adaptações, e chegasse aos moldes do que conhecemos hoje. Desde o ano de 2009, as proporções da avaliação se tornaram ainda maiores, tendo em vista que o resultado do exame está sendo utilizado pela maioria das universidades federais do país como forma de ingresso ao Ensino Superior, em substituição aos exames vestibulares.

Entendendo a importância de tal exame, torna-se relevante conhecer melhor as metodologias adotadas para a avaliação, principalmente ao que tange à concepção de língua utilizada na prova, haja vista que o candidato tem que responder à prova de Linguagens, Códigos e suas Tecnologias e produzir um texto para a prova de redação. E, por ser um instrumento criado com o intuito averiguar os resultados de eficiência da última etapa da educação básica, como consta no PNE (2014-2024), é indissociável discutir as proposituras do exame sem atrelar ao que apregoam os documentos norteadores das políticas públicas educacionais do país, a exemplo dos Parâmetros Curriculares Nacionais (PCN) e do Programa Nacional do Livro Didático (PNLD).

Os PCN são diretrizes elaboradas pelo Governo Federal em conjunto com a sociedade civil, professores e especialistas na área educacional, cujo objetivo é orientar os educadores por meio da normatização de alguns aspectos fundamentais de cada disciplina prevista no currículo escolar. Sem caráter obrigatório, visa subsidiar as discussões em torno dos processos educacionais do país, e se caracteriza por apresentar um tratamento específico para cada área de conhecimento (disciplinas curriculares) que o aluno tem que cursar no ensino básico. No que se refere ao currículo Língua Portuguesa (BRASIL, 2000, p. 5), a primeira orientação parte da concepção de linguagem: "a linguagem é uma herança social, uma 'realidade primeira', que, uma vez assimilada, envolve os indivíduos e faz com que as estruturas mentais, emocionais e perceptivas sejam reguladas pelo seu simbolismo". E, ainda,

Toda linguagem carrega dentro de si uma visão de mundo, prenha de significados e significações e vão além do seu aspecto formal. 0 estudo apenas do aspecto formal, desconsiderando a inter-relação contextual, semântica e gramatical própria da natureza e função da linguagem, desvincula o caráter intrasubjetivo, intersubjetivo e social da linguagem. (BRASIL, 2000, p. 5-6).

Os currículos escolares, os livros didáticos e exames em larga escala devem ser constituídos a partir de uma perspectiva do ensino de língua materna voltado para o contexto variável da língua, não se prendendo à perpetuação dos dogmas da gramática normativa.

É importante apreciar o que os materiais que norteiam a educação básica consideram a respeito das habilidades exigidas no Enem, já que o ensino nas escolas - pelo menos na rede pública - segue essas diretrizes por meio dos livros didáticos, selecionados e distribuídos pelo Programa Nacional do Livro Didático aos alunos da educação básica. A escolha desses é feita pelo programa em ciclos trienais a partir de critérios estabelecidos pelo Ministério da Educação. Na medida em que os documentos norteadores tratam a língua a partir do pluralismo linguístico, a contribuição da Sociolinguística torna-se indispensável, por possibilitar o diálogo entre os parâmetros educacionais, sua aplicação em sala de aula e em avaliações como o Enem. 
Partindo do princípio de que o Enem tem como função primeira de avaliar e, consequentemente, auxiliar na elaboração de políticas públicas destinadas à última etapa da educação básica, e alinhado aos objetivos do projeto "O impacto da prova de redação do Enem no currículo da rede pública estadual de Sergipe", financiado pelo Edital do Programa de Apoio e Desenvolvimento de Políticas Públicas para o Estado (NAPS), da Fundação de Apoio à Pesquisa e Inovação Tecnológica de Sergipe (FAPITEC), a proposta deste trabalho é investigar como se dá o uso dos gêneros textuais como suportes às questões que tratam de variação linguística na prova de Linguagens, Códigos e suas Tecnologias, no período de 1998 a $2012^{1}$.

\section{VARIAÇÃO LINGUÍSTICA E GÊNEROS TEXTUAIS NOS DOCUMENTOS OFICIAIS}

As questões do Enem, diferentemente dos exames vestibulares tradicionais, são caracterizadas por apresentarem enunciados mais extensos, contextualizados e explicativos, e na maioria das vezes, tendo um texto como suporte para resolução das questões. É relevante observar o suporte dado aos candidatos, especificamente ao gênero textual, na definição de Marcuschi (2005, p. 30): "os gêneros não são entidades naturais como as borboletas, as pedras, os rios e as estrelas, mas são artefatos culturais construídos historicamente pelo ser humano". Nessa perspectiva, o gênero textual se caracteriza pela materialização dos textos em situações comunicativas, variando de acordo com a sua funcionalidade.

A denominação gênero textual recobre uma gama de possibilidades: carta, crônica, poema, artigo cien-

1. O desenvolvimento deste projeto está vinculado ao Grupo de Estudos em Linguagem, Interação e Sociedade - GELINS, que também desenvolveu o projeto "Ler+Sergipe: leitura para o letramento e cidadania", financiado pelo Programa Observatório da Educação (edital 38/2010/CAPES/INEP), (ALMEIDA; FREITAG, 2014; FREITAG, 2013; FREITAG, ALMEIDA, ROSÁRIO, 2013). Os resultados de ambos os projetos podem contribuir significativamente para o desenvolvimento de políticas públicas de ensino, especialmente no que diz respeito às avaliações em larga escala e o ensino de língua materna. tífico, bula de remédio, entre muitos outros, favorecem o ensino de língua materna preconizado pelos documentos norteadores, se distanciando dos decorebas gramaticais, e partindo do texto para discutir os conteúdos, como apontado nos PCN do ensino médio.

\begin{abstract}
Os conteúdos tradicionais do ensino de língua, ou seja, a nomenclatura gramatical e história da literatura, são deslocados para um segundo plano. 0 estudo da gramática passa a ser uma estratégia para compreensão/ produção e interpretação de textos (...). A interação é que faz com que a linguagem seja comunicativa. Esse princípio anula qualquer pressuposto que tenta referendar o estudo da língua isolada do ato interlocutivo. (BRASIL, 2000, p. 18).
\end{abstract}

Os PCNEM (2000, p. 22) apontam que, em situação de ensino, o uso da língua materna depende da escolha de gêneros e tipos de discurso, e essas escolhas refletem no domínio de "contatos textuais" não declarados, mas que estão implícitos no texto. "Tais contatos exigem que se fale/escreva desta ou daquela forma, segundo este ou aquele gênero. Disso saem as formas textuais". A partir desta ótica, o uso dos gêneros textuais indica as possibilidades de usos da língua de acordo com o contexto.

No que se refere ao PNLD (BRASIL, 2012, p. 6), o documento Guia para o ensino médio, existe uma colocação das tarefas a serem exercidas pelo docente, favorecer "a prática de análise e reflexão sobre a língua, na medida em que se fizer necessária ao desenvolvimento da proficiência oral e escrita, em compreensão e produção de textos". Essa colocação corrobora com uma das premissas dos parâmetros de Língua Portuguesa, que indicam a importância de além de abordar textos da tradição literária brasileira, fazer uma abordagem mais intensa dos gêneros em circulação nas esferas públicas, e principalmente, com as formas de expressão e os gêneros próprios das culturas juvenis.

No documento, gênero textual é entendido como um instrumento importante para a reflexão sobre a língua e a linguagem, no ensino de língua portuguesa, 
que seja capaz de considerar as relações que se estabelecem entre a linguagem verbal e outras linguagens, no processo de construção dos sentidos de um texto.

Diante das colocações dos documentos, torna-se evidente a colaboração que os gêneros trazem às questões do exame, haja vista que o que se propõe nas habilidades a serem atingidas pelo candidato e nas orientações dos documentos norteadores é a discussão da língua materna a partir dos contextos das demandas sociais, sejam eles orais ou escritos.

Se os gêneros textuais são a forma como a língua se organiza para se manifestar nas mais diver- sas situações de comunicação, cada gênero textual possui seu próprio estilo e estrutura, possibilitando, assim, que seja identificado por meio de suas características. A abordagem de um gênero específico no enunciado de uma questão vai conduzir a abordagem variacionista desta, se será o romance, o artigo acadêmico, o conto e a receita culinária, que são gêneros escritos, ou ainda textos orais como a aula, o debate, a palestra, entre outros. E mais importante que isso, o contexto que retratam, como evidenciado na habilidade de número 25 da matriz do Enem - Identificar, em textos de diferentes gêneros, as marcas linguísticas que singularizam as variedades linguísticas sociais, regionais e de registro.

Figura 1 - Questão nº 14 da prova azul de Linguagens, Códigos e suas Tecnologias
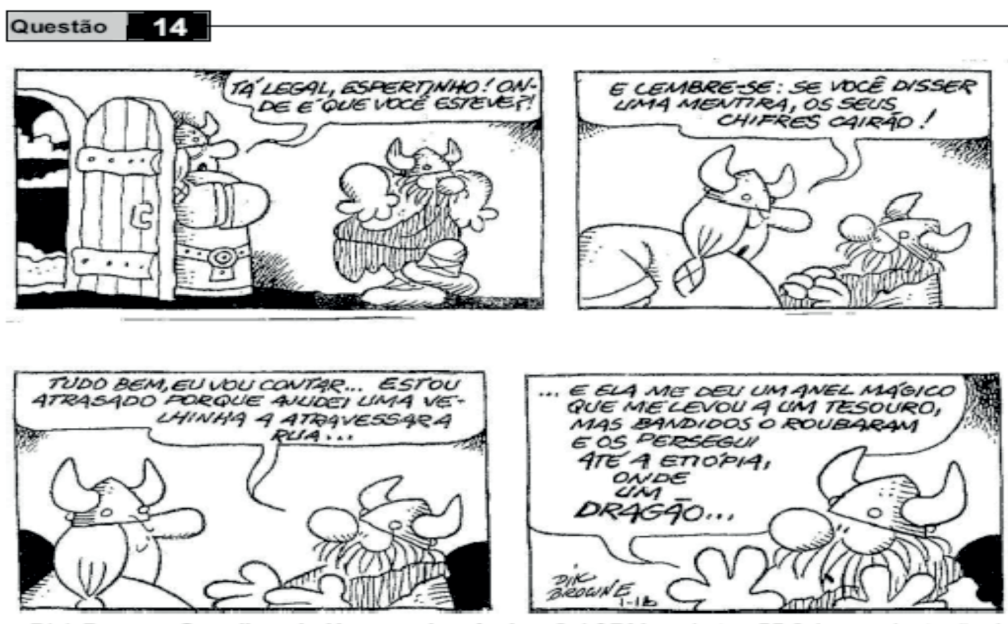

Dick Browne. O melhor de Hagar, o horrivel, v. 2. L\&PM pocket, p.55-6 (com adaptaçōes).

Assinale o trecho do diálogo que apresenta um registro informal, ou coloquial, da linguagem.

ه “Tá legal, espertinho! Onde é que você esteve?!"

(B) "E lembre-se: se você disser uma mentira, os seus chifres cairão!" ○ "Estou atrasado porque ajudei uma velhinha a

D “...e ela me deu um anel mágico que me levou a um tesouro"

๑ "mas bandidos o roubaram e os persegui até a Etiópia, onde um dragão..."

Fonte: Enem (2008, p. 6). 
As histórias em quadrinhos, por se tratarem de um gênero textual de comunicação visual e elementos verbais que retratam uma narrativa, têm como predominância o contexto dialogal, ou seja, a oralidade. No caso do quadrinho de Hagar na questão 14 da prova do Enem de 2008, reproduzida na Figura 1, o dialógo acontece entre marido e mulher e tem como tema um assunto corriqueiro entre cônjuges: a indagação da esposa a respeito da saída do marido. A contextualização do gênero textual utilizado, do enredo e das personagens é, nesse situação, favorável para discussão em torno da variação linguística no que diz respeito à informalidade e uso coloquial, uma vez que por meio dos elementos que compõem a questão, seja eles im- plícitos ou explícitos, é possível tratar da variabilidade da língua de acordo com os contextos de uso.

Outra possibilidade de abordagem da língua contextualizada é encontrada na questão de número 127 , da prova de 2010, que tem como suporte de texto motivador o gênero carta, que se caracteriza por normalmente ser escrita em primeira pessoa, e visar um tipo de leitor. Nessa perspectiva, o gênero carta, carrega o critério de intencionalidade na essência, haja vista que as marcas linguísticas que carrega vão depender bastante do destinatário, do assunto a ser tratado, entre outros, definirá o seu grau de formalidade.

Figura 2 - Questão nº 127 da prova amarela de Linguagens, Códigos e suas Tecnologias

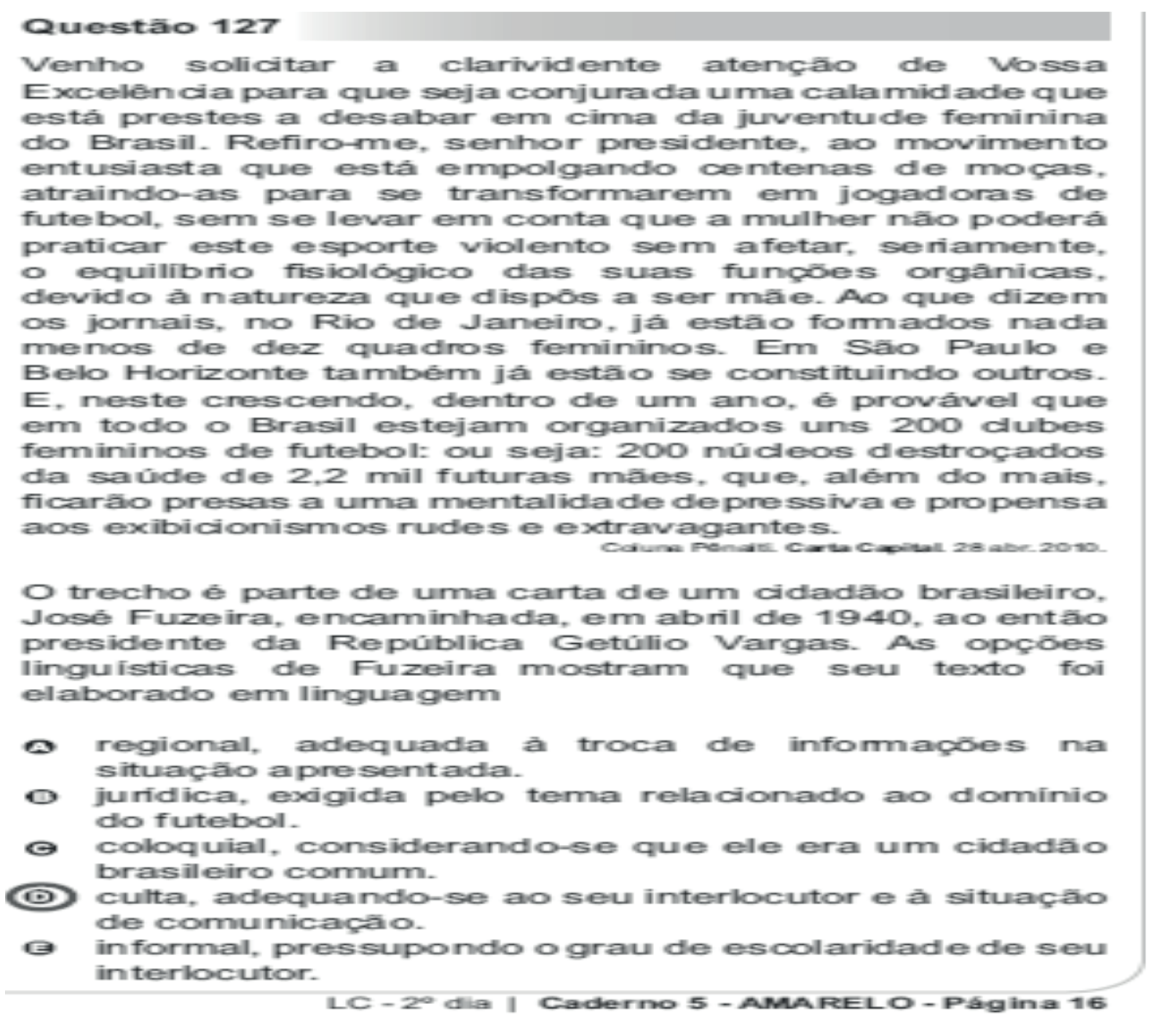

Fonte: Enem (2010, p. 16). 
O exemplo trazido na prova de 2010 trata-se de uma carta destinada ao então presidente do Brasil Getúlio Vargas e por esse motivo o reporte linguístico utilizado pelo remetente foi a linguagem culta.

A fim de verificar a presença dos gêneros textuais nas questões de variação linguística, considerando a diversidade e a variedade preconizada nos documentos norteadores, procedemos ao levantamento da ocorrência de questões de variação linguística por ano no período de 2000 a 2012 e observamos o gênero textual utilizado como suporte no texto motivador de cada questão².

\section{GÊNEROS TEXTUAIS NAS QUESTÕES VARIAÇÃO LINGUISTICAS DO ENEM}

A presença dos gêneros textuais nas questões que tratam de variação linguística na prova de Linguagem, Códigos e suas Tecnologias do Enem pode ser vista na wordcloud da figura $2^{3}$.

Figura 3 - Wordcloud dos gêneros textuais suporte às questões de variação do Enem de 2000 a 2012

\section{artigo_acadêmico \\ artigo_de_opinião canção carta charge CONtO crônica diálogo gramática poema quadrinho relato_pessoal romancetexto_informativo \\ Fonte: Elaboração própria}

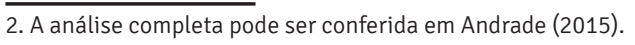

3. Foram identificadas 35 questões de variação linguísticas no período e, dada a limitação do tamanho da amostra, utilizamos a técnica estatística de wordcloud (outagcloud), que se caracteriza pela representação visual de dados de um determinado texto/arquivo através de "nuvens de palavras", usadas para descrever palavras-chave (tags), que possibilita maior visibilidade aos resultados. Esta metodologia tem sido adotada em diferentes áreas para dar suporte às análises de conteúdo de natureza qualitativa, como pode ser visto em Carvalho Jr e outros autores (2012), na saúde; Araújo e outros autores (2014), na contabilidade; Bernardes e outros autores (2013), no design; e, inclusive, nos estudos da linguagem, como em Garavello (2009) e Andrade (2015). Procuramos uma ferramenta que gerasse "nuvens" para o banco de dados de nossa codificação das questões, possibilitando, assim, a visualização e interpretação do conteúdo a partir dos termos mais recorrentes. A fonte de cada palavra "nuvem" é disponibilizada de acordo com a sua ocorrência ou relevância, ou seja, o tamanho da fonte representa o número de vezes que as tags apareceram no texto.
Diante da gama de gêneros existentes, nas 35 questões foi possível identificar 15 gêneros textuais diferentes, com maior ocorrência do artigo acadêmico e do texto informativo, que se caracterizam pela discussão técnica de ideias e resultados a partir da abordagem de um tema específico. Dentre as questões, é preciso destacar aquelas que tratam da variação a partir de discussões e definições de reportes teóricos da linguística, como a 127 da prova de 2011.

Figura 4 - Questão nº 127 da prova azul de Linguagens, Códigos e suas Tecnologias

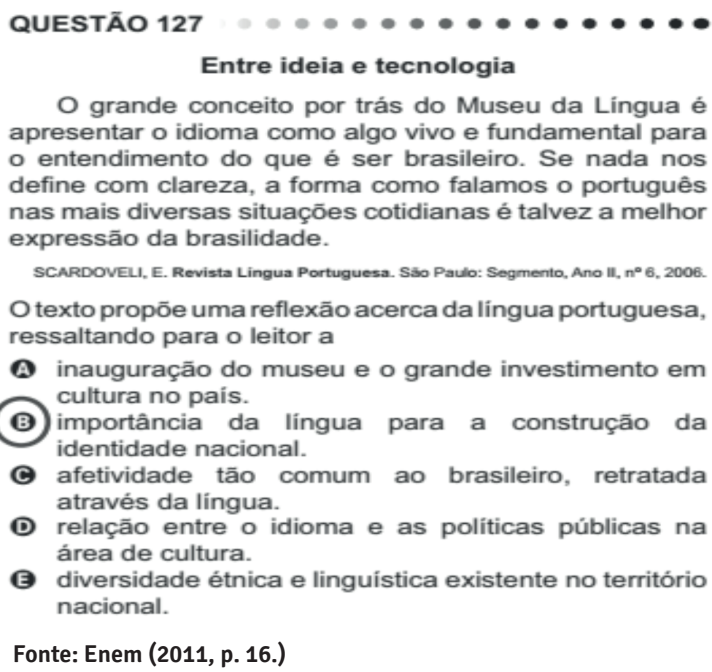

O grande conceito por trás do Museu da Língua é apresentar o idioma como algo vivo e fundamental para o entendimento do que é ser brasileiro. Se nada nos define com clareza, a forma como falamos o português nas mais diversas situaçōes cotidianas é talvez a melhor expressāo da brasilidade.

SCARDOVEU, E. Revista Lingua Portuguesa. Säo Paulo: Segmento, Ano II, nº 6, 2006.

O texto propōe uma reflexāo acerca da lingua portuguesa, ressaltando para o leitor a

Q inauguração do museu e o grande investimento em cultura no pais.

B) importância da língua para a construçāo da identidade nacional.

C afetividade tão comum ao brasileiro, retratada através da língua.

- relação entre o idioma e as políticas públicas na área de cultura.

๑ diversidade étnica e linguística existente no território nacional.

Fonte: Enem (2011, p. 16.)

Com a finalidade de expor proposições a respeito da língua brasileira e suas formas (variantes), o autor do texto informativo publicado em revista e utilizado como suporte na questão 127 se utiliza do registro formal da língua, registro esse preconizado na linguagem jornalística, para abordar a língua como algo "vivo" e constantemente em transformação. Porém, não existe nenhuma problematização em torno da temática, o que caracteriza a questão como de cunho interpretativo, haja vista as alternativas de resposta que são apresentadas ao candidato.

As demais questões se configuram pela discussão variacionista a partir de uma perspectiva mais 
literária dos gêneros conto, romance e poema, os mais recorrentes na wordcloud. Os dois primeiros enquadrando-se no gênero literário narrativo e caracterizam-se, respectivamente, por apresentar traços da narrativa oral e por esse motivo carregar uma linguagem simples e acessível e atender a critérios narrativos de ambientação e espaços claramente definidos. Já o poema, por ser do gênero literário lírico, constitui expressão estética por meio da língua.

Figura 5 - Questão no 111 da prova azul de Linguagens, Códigos e suas Tecnologias

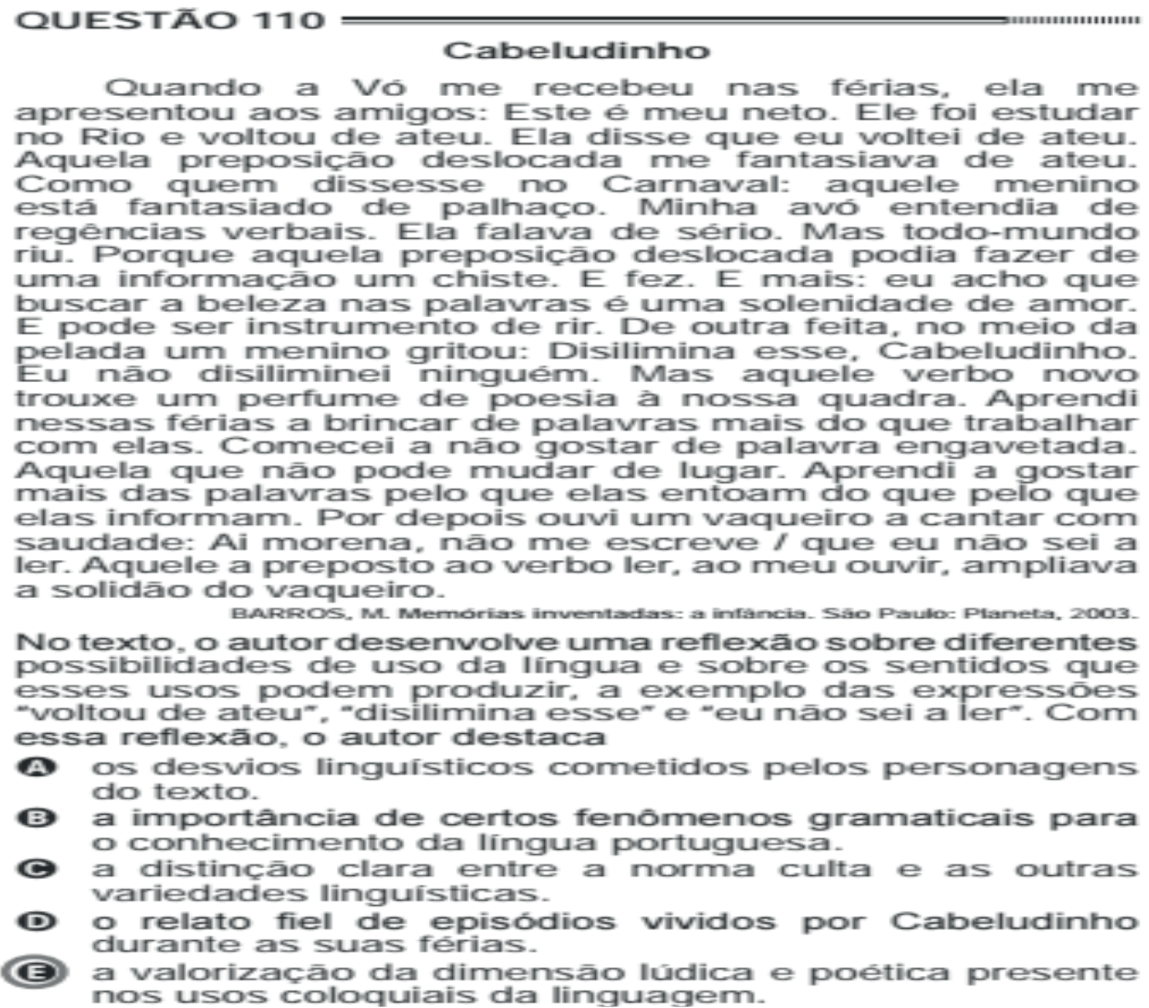

Fonte: Enem (2012, p. 10).

O uso de expressões como "voltou de ateu”, "disilimina esse" e "eu não sei a ler", presentes na produção do poeta Manoel de Barros, e enfatizadas na pergunta da questão, levam à resposta de letra $E$ do gabarito, reforçando a ideia de uso coloquial a serviço do efeito poético. Mais uma vez, a abordagem sociolinguística da língua se restringe a uma discussão pouco problematizadora e restritiva.
É importante tratar da possibilidade que o gênero literário dá ao autor de se utilizar de efeitos linguísticos, estéticos e de sentido, concedendo que a linguagem empregada em uma produção atenda as intenções de quem escreveu o texto, cabendo a utilização da linguagem formal ou informal como recurso estilístico, porém o ideal não é parar nesse ponto. 
Além dos já mencionados, identificamos a presença de gêneros textuais orais: diálogo, entrevista, canção. Desses, alguns são mais formais e se tornam instrumen- to do domínio de atividades de linguagem, que precisam ser apoiados em gêneros escritos, e outros menos formais, indicando situações de comunicação corriqueiras.

Figura 6 - Questão nº 128 da prova azul de Linguagens, Códigos e suas Tecnologias$$
\text { QUESTÃO } 128
$$

\section{Entrevista com Marcos Bagno}

Pode parecer inacreditável, mas muitas das prescriçoes da pedagogia tradicional da língua ate hoje se baseiam nos usos que os escritores portugueses do século XIX faziam da língua. Se tantas pessoas condenam, por exemplo, o uso do verbo "ter" no lugar de "haver", como em "hoje tem feijoada", e simplesmente porque os portugueses, em dado momento da história de sua língua, deixaram de fazer esse uso existencial do verbo "ter".

No entanto, temos registros escritos da epoca medieval em que aparecem centenas desses usos. Se nós, brasileiros, assim como os falantes africanos de português, usamos até hoje o verbo "ter" como existencial é porque recebemos esses usos de nossos excolonizadores. Năo faz sentido imaginar que brasileiros, angolanos e moçambicanos decidiram se juntar para "errar" na mesma coisa. E assim acontece com muitas outras coisas: regencias verbais, colocação pronominal, concordancias nominais e verbais etc. Temos uma língua própria, mas ainda somos obrigados a seguir uma gramática normativa de outra língua diferente. As vésperas de comemorarmos nosso bicentenário de independencia, nầ faz sentido continuar rejeitando o que é nosso para só aceitar o que vem de fora.

Năo faz sentido rejeitar a língua de 190 milhőes de brasileiros para so considerar certo o que é usado por menos de dez milhőes de portugueses. So na cidade de Săo Paulo temos mais falantes de portugues que em toda a Europa!

Informativo Parabola Editorial, $s / d$.
\end{abstract}

Fonte: Enem (2012, p. 14).

Na questão de número 128, que tem como suporte textual o gênero entrevista, o candidato deveria marcar a alternativa $A$, a qual indica a linguagem como situação comunicativa, e que no caso do gênero proposto, deve atender a norma padrão. Em linhas gerais, uma questão que traz um trecho de uma entrevista, cujo entrevistado suscita a discussão acerca da urgência em se aceitar a Língua Portuguesa prati-
Informativo Parabola Editorial, s/d.

Na entrevista, o autor defende o uso de formas linguisticas coloquiais e faz uso da norma padrão em toda a extensão do texto. Isso pode ser explicado pelo fato de que ele

(A) adapta o nivel de linguagem à situação comunicativa, uma vez que o gênero entrevista requer o uso da norma padrão.

B apresenta argumentos carentes de comprovação científica e, por isso, defende um ponto de vista difícil de ser verificado na materialidade do texto.

C propőe que o padrão normativo deve ser usado por falantes escolarizados como ele, enquanto a norma coloquial deve ser usada por falantes nâo escolarizados.

D acredita que a língua genuinamente brasileira está em construçăo, o que o obriga a incorporar em seu cotidiano a gramática normativa do portugues europeu.

E defende que a quantidade de falantes do portugues brasileiro ainda é insuficiente para acabar com a hegemonia do antigo colonizador.

cada no Brasil, e além disso, considerando sua heterogeneidade, culmina em uma abordagem normativa, contradizendo uma afirmação contida no próprio texto: "Temos uma língua própria, mas somos obrigados a seguir uma gramática normativa de outra língua diferente”. E ainda, apresenta a norma padrão como uma variante, mas, o que se prática como norma padrão no português não é uma variedade da lín- 
gua, mas um constructo que serve de referência para um processo de uniformização.

A observação do suporte textual utilizado nas questões atrelado aos contínuos de Bortoni-Ricardo (2004) levam a identificação de uma tendência no exame. Quando os gêneros textuais utilizados são de fundamentação mais informal, mais voltados para a oralidade, a exemplo das histórias em quadrinho, canção, charge e relato pessoal, existe uma forte ocorrência do contínuo de oralidade-letramento, caracterizado como eventos de comunicação mediados ou não pela língua escrita. Já quando os gêneros textuais tendem a formalidade, como o poema, conto, artigo de opinião e artigo acadêmico, há a prevalência do contínuo de monitoração estilística, esse relacionado ao grau de atenção e de planejamento conferidos pelo falante.

E, por fim, o contínuo de urbanização, ocorre em gêneros tanto mais formais, quanto informais, poema e história em quadrinho, não havendo prevalência entre um ou outro, talvez esse fato seja justificado pelo modo como o contínuo é abordado, em todas as questões, está voltado para a discussão do preconceito de discriminação linguística, ou seja, envolto a uma perspectiva normativa.

De modo recorrente, o que se viu nas questões observadas quanto ao suporte dado pelo texto motivador, foi uma tendência de levar a discussão sociolinguística a uma abordagem pouco reflexiva sobre o uso da língua.

\section{CONSIDERAÇ̃̃ES FINAIS}

A temática variação linguística vem sendo tratada na avaliação, fato refletivo das orientações dos documentos norteadores, se materializando em torno de situações reais de comunicação por intermédio de recursos textuais, a exemplo das histórias em quadrinho e diálogos, abordando a oralidade e informalidade da língua. No entanto, apesar das orientações dos documentos norteadores e da avaliação, ainda é preciso promover alterações necessárias no ensino de Língua Portuguesa.
O trabalho da escola para o ensino de língua materna deve ser urgente quanto ao atendimento das novas demandas, atendendo à dinâmica social de mudança, uma vez que não cabe mais conceber a língua como algo estático. É preciso combater as práticas vigentes de ensino pautado em uma única língua, padronizada, com a justificativa de ser mantenedora da uniformidade do idioma do País. Isto ainda se perpetua na prova do Enem, como vimos, pela correlação entre gêneros mais formais, como carta, com situações formais de língua e gêneros mais informais, como quadrinhos, com situações informais de língua. Esta não pode ser a única a ser considerada, pois como foi constatado, mesmo nas questões em que a variação linguística é o foco, a presença normativa se fez latente.

\section{REFERÊNCIAS}

ALMEIDA, Ayane Nazarela Santos; FREITAG, Raquel Meister Ko. Narrativas de alfabetizandos e sua proficiência linguística. Linguagem \& Ensino, v.17, Pelotas-RS, 2014. p.151-171.

\section{ANDRADE, Sammela Rejane Jesus. Competências}

linguísticas na prova do Enem: uma abordagem sociolinguística. 2015. Dissertação (Mestrado em Letras) - Universidade Federal de Sergipe, 2015.

ARAÚJO, Kleber Domingos de. et al. Percepção dos impactos da adoção das IFRS na contabilidade gerencial sob a ótica dos professores de programas de pós-graduação stricto sensu em contabilidade.

Revista Universo Contábil, v.10, n.2, Blumenau-SC, 2014. p.105-124.

BERNARDES, Mauricio Moreira e Silva; OLIVEIRA, Geisa Gaiger de; RUECKER, Stan; SATO, Keiichi. Identificação de pesquisas estratégicas em gestão de design direcionadas ao aumento da competitividade de micro e pequenas empresas brasileiras. Design \& Tecnologia, v.3, n.5, Porto Alegre-RS, 2013. p.24-34. 
BORTONI-RICARDO, Stella Maris. Um modelo para a análise sociolinguística do português do Brasil. In: BAGNO, Marcos (Org.). Linguística da norma. São Paulo: Loyola, 2004. p.333-347.

BRASIL. Ministério da Educação. Secretaria de Educação Média e Tecnológica. Parâmetros Curriculares Nacionais (Ensino Médio). Brasília: MEC, 2000.

BRASIL. Ministério da Educação. Secretaria da Educação Média e Tecnológica. Guia de livros didáticos: PNLD 2012: Língua Portuguesa. Brasília: Ministério da Educação, Secretaria de Educação Básica, 2011.

CARVALHO Jr, Paulo M. et al. Avaliação do programa de residência multiprofissional em saúde da família: uma análise qualitativa através de duas técnicas.

Revista Hospital Universitário Pedro Ernesto, v.11, n.1, Rio de Janeiro, 2012. p.114-119.

FREITAG, Raquel Meister Ko. Leitura, letramento e cidadania: explorando a Provinha Brasil. Curitiba: Appris, 2013.
FREITAG, Raquel Meister Ko. ALMEIDA, Ayane Nazarela Santos. ROSÁRIO, Mônica Maria Soares. Contribuições para o aprimoramento da Provinha Brasil enquanto instrumento diagnóstico do nível de alfabetização e letramento nas séries iniciais.

Revista Brasileira de Estudos Pedagógicos, v.94, n.237, Campinas-SP, 2013. p.390-41.

FREITAG, Raquel Meister Ko. CYRANKA, Lúcia Mendonça. Sociolinguística variacionista e educacional: tendências metodológicas.In: GONÇALVES, A.V. GÓIS, M. L. de S. (Org.). Ciências da linguagem: o fazer científico, v.2, Campinas-SP, 2014. p.249-280.

\section{GARAVELLO, Murilo de Paula Eduardo. Os blogs e} o jornalismo de texto: a campanha para eleição presidencial de 2006 no Brasil. 2009. Dissertação (Mestrado em Ciências da Comunicação) Universidade de São Paulo, 2009.

MARCUSCHI, Luiz Antônio. Gêneros textuais: definição e funcionalidade. In: DIONÍSIO, A. P.; MACHADO, A. R.; BEZERRA, M. A. (Org.). Gêneros

textuais e ensino. 4.ed. Rio de Janeiro: Lucerna, 2005. 